\title{
技術報告
}

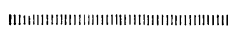

\section{ポジトロンェミッショントモグラフィ測定におけるポジトロン 放射ラジオアイントープ搬送パイプの遮蔽}

\author{
蜂谷武憲, 羽上栄一, 庄司安明, 相沢康夫, 菅野 厳, 上村和夫, \\ 半田昌彦*, 森 純一*, 深川明久* \\ 秋田県立脳血管研究センター放射線科 010 秋田市千秋久保田町 6-10 \\ *千代田保安用品㑣 113 東京都文京区本郷 3-40-11 \\ 1989年 5 月 26 日 受理
}

Key Words : radiation shields, transportation pipe, compact cyclotron, oxygen-15 gas, positron emission tomography

1. はじめに

Positron emission tomography (PET) は病院内に 超小型サイクロトロンを設置して短半減期 RI を生産 し, ポジトンCTにより, 生体の生理学的 情報を定量的に検查する測定法として行われ ている。われわれの施設でも昭和58年 4 月よ り，主に ${ }^{15} \mathrm{O}$ 標識ガスを用いた脳循環測定を 行ってきだ。この検査には $\mathrm{C}^{15} \mathrm{O}_{2},{ }^{15} \mathrm{O}_{2}, \mathrm{C}^{15} \mathrm{O}$ の標識ガスを被検者に吸入させて行うもの と, $\mathrm{H}_{2}{ }^{15} \mathrm{O}$ のように, 注射薬に合成し, 静脈 注射により投与する方法がある。 ${ }^{15} \mathrm{O}$ 標識が スによる PET 測定の場合, サイクロトロン で生産された RI は Fig. 1 のように自動合成 装置で標識後, PET 測定室に RI 搬送パイプ で搬送され，被検者に投与される。RI 搬送 パイプには，内径 $2.2 \mathrm{~mm}$ のステンレス管と テフロン管を使用している2)。当施設のRI 搬 送パイプの遮蔽は Fig. 1 のよらに $5 \mathrm{~cm}$ 厚の 鉛で行っており，一部は厚さ $50 \mathrm{~cm}$ のコンク リートで行っている。この遮蔽体の厚さは, 安全を考慮した計算から算出したものであっ て，実測によるデータから決めたものではな い。ポジトロン放射 RI の遮蔽体に対する実 測の資料はなく，計算には， $\gamma$ 線エネルギ - $662 \mathrm{keV}$ の ${ }^{137} \mathrm{Cs}$ を用いている。このため ${ }^{15} \mathrm{O}$ を用いた鉛とコンクリートに対する遮蔽 の実測値に基づく検討を行った。
2. 方 法

$2 \cdot 1$ 使用装置, 機材

(1) サイクロトロン $\mathrm{BC}-168$ (日本製鋼所製) ${ }^{3)}$

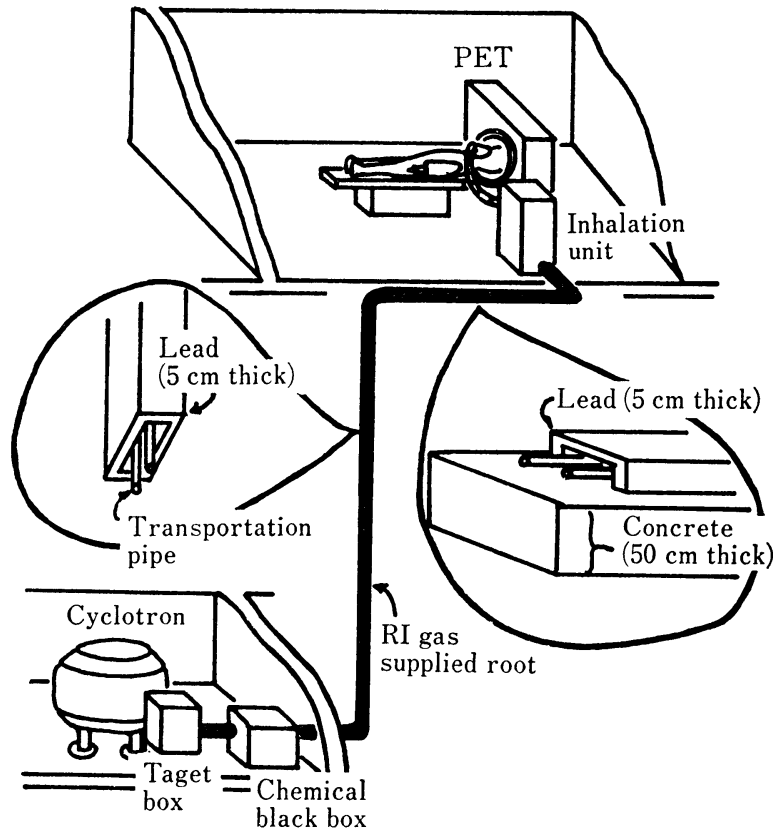

Fig. 1 The schema of the supply route of the positron emitting radioisotopes from cyclotron to the inhalation unit in PET room in our system. The radiation shields used are $5 \mathrm{~cm}$ thick lead, and partly $50 \mathrm{~cm}$ thick concrete. 
（2）使用 RI

${ }^{15} \mathrm{O}_{2} \quad 1.85 \mathrm{GBq} / \mathrm{min}$ $555 \mathrm{MBq} / \mathrm{min}$

（3）遮蔽体 鉛

$2,4,6,10,20$, $30,40(\mathrm{~mm})$ コンクリート

$10,15,20,30,40(\mathrm{~cm})$

(4) 測定器

電離槽サーベイメータ

ICS-151 (Aloka 製)

\section{$2 \cdot 2$ 測定方法}

Fig. 2 に測定のようすを示す。サイクロト ロン室からPET室まで設置された全長約 $30 \mathrm{~m}$ の RI 搬送パイプに対し鉛の遮蔽体が敷設さ れている。一部に点検のための点検口があ り, 長さ $15 \mathrm{~cm}$ の遮蔽をとり外せる部分があ る。測定はこの点検口に，鉛およびュンクリ 一トを置いて，それぞれ厚さを変えて行っ た。 RI量はサイクロトロン BC-168により生 産された ${ }^{15} \mathrm{O}$ 標識の ${ }^{15} \mathrm{O}_{2}$ を用い, $1.85 \mathrm{GBq} /$ $\min$ と実際の PET 測定使用量 $555 \mathrm{MBq} / \mathrm{min}$ を使用した。なお，555 MBq/min は実際の PET測定中の線量であり，測定はいずれも連 続供給下で行った。PET室に送られたRIは, ガス吸入装置の切り換えにより, 内径 $8 \mathrm{~mm}$ の廃棄ガス回収パイプで Fig. 2 のよらに RI 搬送パイプと同じ遮蔽体内を経由してサイク ロトロン室内の廃棄ガス貯蔵タンクに回収保 管する。このため本測定は RI ガスの供給と 回収を含めた遮蔽体の遮蔽能力を測定するこ とになる。放射線障害防止法，医療法がとも に昭和63年に改正され, 平成元年 4 月に施行

された。これに伴い外部線量は $1 \mathrm{~cm}$ 深部線量当量 (以 下 $H_{1 \mathrm{~cm}}$ 線量当量 $)^{4)}$,5) が導入された。本测定は線量 率表示のサ一ベイメータによる測定のため，測定值を 計算により $H_{1 \mathrm{~cm}}$ 線量当量率に変換した。

\section{3. 結 果}

\section{$3 \cdot 1$ 線量率測定結果}

線量率表示による結果を Table 1 の上段に $\mathrm{mR} / \mathrm{h}$ で 示した。 ${ }^{15} \mathrm{O}_{2}$ ガス $1.85 \mathrm{GBq} / \mathrm{min}$ 供給下での測定結果 はつぎのとおりであった。遮蔽体なしでは $3.3 \mathrm{mR} / \mathrm{h}$ 。 鉛遮蔽の場合は，厚さ $1 \mathrm{~cm}$ で $0.42 \mathrm{mR} / \mathrm{h}, 2 \mathrm{~cm}$ で 0.11 $\mathrm{mR} / \mathrm{h}, 3 \mathrm{~cm}$ で $0.03 \mathrm{mR} / \mathrm{h}, 4 \mathrm{~cm}$ で $0.01 \mathrm{mR} / \mathrm{h}, 5 \mathrm{~cm}$ では検出限界以下であった。コンクリートに対して

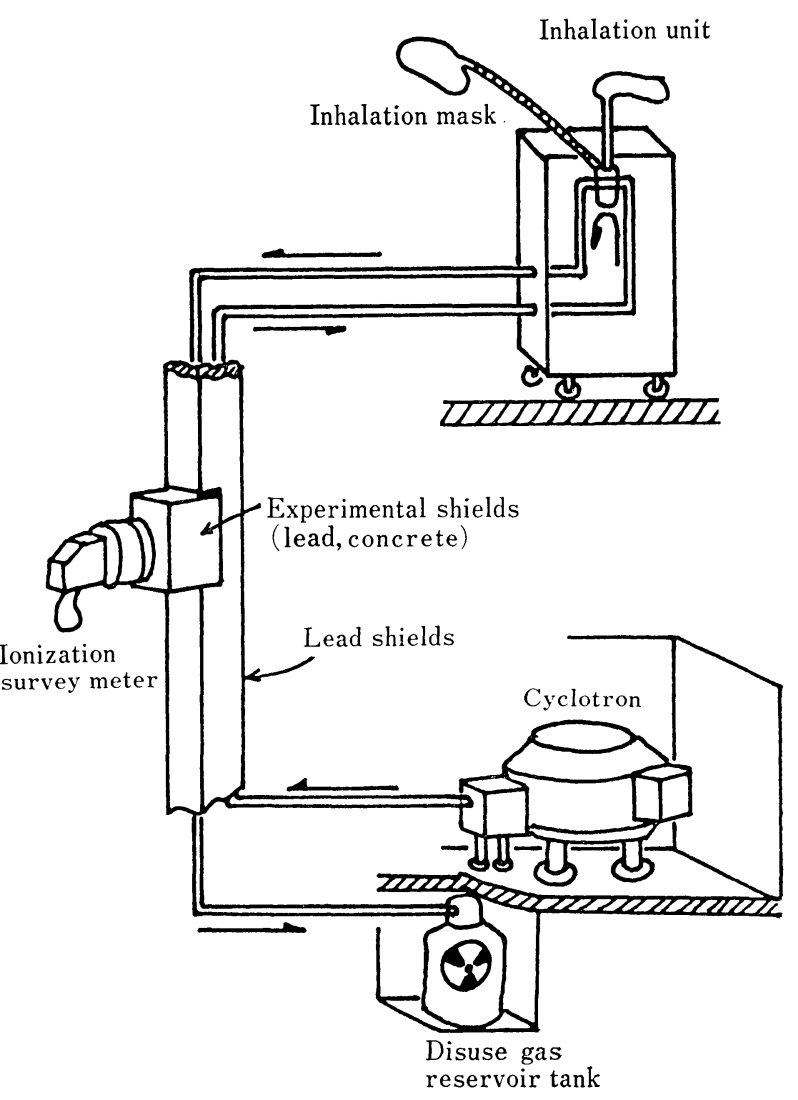

Fig. 2 The schema of the measurement of radiation-doses for a transportation pipe.

The ${ }^{15} \mathrm{O}_{2}$ gas produced by the compact cyclotron was supplied to the inhalation unit via transportation pipe, and was collected to the reservoir tank in the cyclotron room via the same route. Therefore, the radiation dose measured included both of the supply and collection.

は, 厚さ $10 \mathrm{~cm} て ゙ 0.38 \mathrm{mR} / \mathrm{h}, 20 \mathrm{~cm}$ で $0.06 \mathrm{mR} / \mathrm{h}, 30$ $\mathrm{cm}$ で0.01 mR/hであった。 $40 \mathrm{~cm}$ では検出限界以下で あった。実際の PET 測定 $555 \mathrm{MBq} / \mathrm{min}$ での测定結果 は鉛遮蔽では厚さ $1 \mathrm{~cm}$ で $0.04 \mathrm{mR} / \mathrm{h}, 2 \mathrm{~cm}$ で $0.01 \mathrm{mR} /$ $\mathrm{h}$, コンクリートでは厚さ $10 \mathrm{~cm}$ で $0.06 \mathrm{mR} / \mathrm{h}, 20 \mathrm{~cm}$

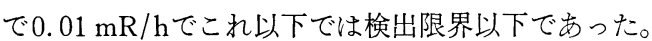
遮蔽体なしでは $0.6 \mathrm{mR} / \mathrm{h}$ であった。

$3 \cdot 2$ 線量当量率表示による測定結果

$H_{1 \mathrm{~cm}}$ 線量当量率への変換はつぎのように行った すなわち, $H_{1 \mathrm{~cm}}$ 線量当量率は, 測定器による照射線 量率の正味指示值を $P_{\mathrm{x}}$, 測定器のエネルギーに応じ た換算係数を $f_{\mathrm{PX}}, H_{1 \mathrm{~cm}}$ 線量当量照射線量換算係数を 
Table 1 The dose rate and dose equivalent rate for radiation shields of transportation pipe

\begin{tabular}{|c|c|c|c|c|c|c|c|c|c|}
\hline \multirow{2}{*}{$\begin{array}{c}{ }^{15} \mathrm{O}_{2} \\
\text { Activity } \\
(\mathrm{MBq} / \mathrm{min})\end{array}$} & \multicolumn{9}{|c|}{ Thickness of shields } \\
\hline & $\begin{array}{l}\text { No } \\
\text { shields }\end{array}$ & 1 & 2 & Lead & 3 & ${ }_{4}^{(\mathrm{cm})}$ & 10 & $\begin{array}{c}\text { Concrete } \\
20\end{array}$ & $30^{(\mathrm{cm})}$ \\
\hline 555 & $\begin{array}{c}(\mathrm{mR} / \mathrm{h}) \\
0.6\end{array}$ & 0.04 & 0.01 & & - & $(\mathrm{mR} / \mathrm{h})$ & 0.06 & 0.01 & $(\mathrm{mR} / \mathrm{h})$ \\
\hline 1850 & 3.3 & 0.42 & 0.11 & & 0.03 & 0.01 & 0.38 & 0.06 & 0.01 \\
\hline 555 & $\begin{array}{l}(\mu \mathrm{Sv} / \mathrm{w}) \\
305.3\end{array}$ & 20.3 & 5.1 & & - & $(\mu \mathrm{Sv} / \mathrm{w})$ & 30.5 & 5.1 & $\begin{array}{c}(\mu \mathrm{Sv} / \mathrm{w}) \\
-\end{array}$ \\
\hline 1850 & 1679.0 & 213.7 & 56.0 & & 15.3 & 5.0 & 193.3 & 30.5 & 5.1 \\
\hline
\end{tabular}

$f_{1 \mathrm{~cm}}$ とすると次式で求まる。

$$
H_{1 \mathrm{~cm}}=P_{\mathrm{x}} \cdot f_{\mathrm{Px}} \cdot f_{1 \mathrm{~cm}}=10.6 \cdot P_{\mathrm{x}}(\mu \mathrm{Sv} / \mathrm{h})
$$

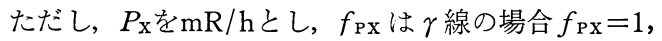
$f_{1 \mathrm{~cm}}$ は500 keVで $10.6 \mu \mathrm{Sv} / \mathrm{mR}$ である。これより求め た 1 週 48 時間当たりの $H_{1 \mathrm{~cm}}$ 線量当量率 $(\mu \mathrm{Sv} / \mathrm{w})$ を Table 1 の下段に, 遮蔽効果は Fig. 3 および Fig. 4 に示した。 $1.85 \mathrm{GBq} / \mathrm{min}$ 供給時では，遮蔽体なしで $1.679 \mathrm{mSv} / \mathrm{w}$ ，鉛遮蔽体 $1 \mathrm{~cm}$ で $213.7 \mu \mathrm{Sv} / \mathrm{w}, 2 \mathrm{~cm}$ で $56 \mu \mathrm{Sv} / \mathrm{w}, 3 \mathrm{~cm}$ で $15.3 \mu \mathrm{Sv} / \mathrm{w}, 4 \mathrm{~cm}$ で $5 \mu \mathrm{Sv} / \mathrm{w}$ あり,コンクリートに対しては厚さ $10 \mathrm{~cm}$ で $193.3 \mu \mathrm{Sv} /$ $\mathrm{w}, 20 \mathrm{~cm}$ で $30.5 \mu \mathrm{Sv} / \mathrm{w}, 30 \mathrm{~cm}$ で $5.1 \mu \mathrm{Sv} / \mathrm{w}$ である。 $555 \mathrm{MBq}$ 供給時は，遮蔽体なしでは $305.3 \mu \mathrm{Sv} / \mathrm{w}$ で，

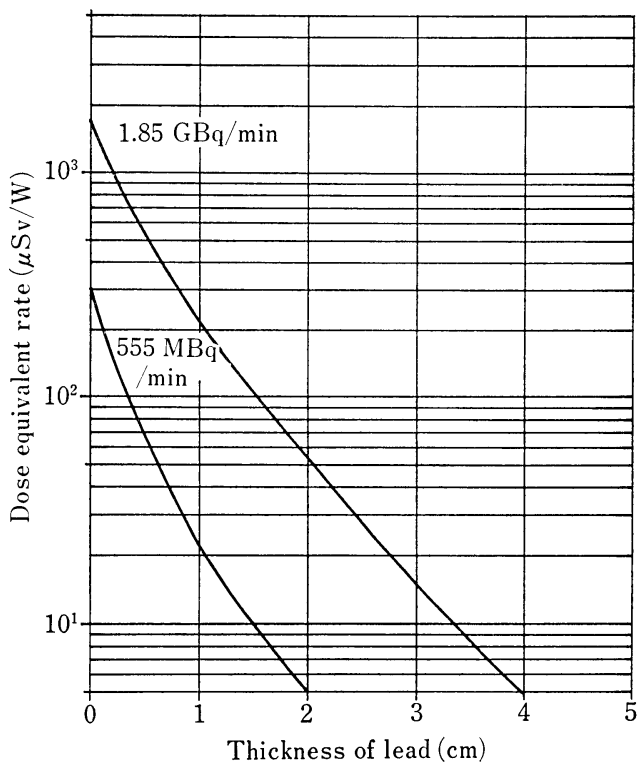

Fig. 3 The dose equivalent rate versus lead shields thickness for continuous supply of $1.85 \mathrm{GBq} / \mathrm{min}{ }^{15} \mathrm{O}_{2}$ (top) and 555 $\mathrm{MBq} / \min { }^{15} \mathrm{O}_{2}$ (bottom).
鉛厚 $1 \mathrm{~cm}$ で $20.3 \mu \mathrm{Sv} / \mathrm{w}, 2 \mathrm{~cm}$ で $5.1 \mu \mathrm{Sv} / \mathrm{w}$ ，コンクリ ート厚 $10 \mathrm{~cm}$ では $30.5 \mu \mathrm{Sv} / \mathrm{w}, 20 \mathrm{~cm}$ で $5.1 \mu \mathrm{Sv} / \mathrm{w}$ とな る。

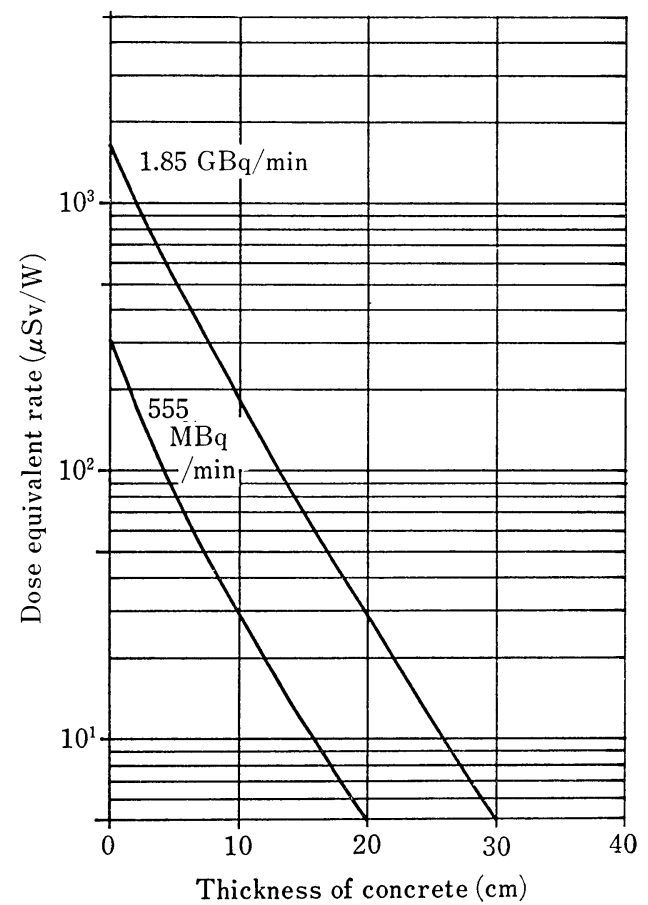

Fig. 4 The dose equivalent rate versus concrete shields thickness for continuous supply of $1.85 \mathrm{GBq} / \mathrm{min}{ }^{15} \mathrm{O}_{2}$ (top) and 555 $\mathrm{MBq} / \mathrm{min}{ }^{15} \mathrm{O}_{2}$ (bottom).

\section{4. 考 察}

管理区域内の RI 使用室における法令上の遮蔽体等 の規制は $1 \mathrm{mSv} / \mathrm{w}$ である ${ }^{4)}$,5)。われわれが脳循環測定 で行っている持続吸入法による最大連続供給 RI 量は ${ }^{15} \mathrm{O}_{2}$ を用いた脳酸素消費量測定に使用する $555 \mathrm{MBq} /$ $\min$ である。この約 3.3 倍の $1.85 \mathrm{GBq} / \mathrm{min}$ の測定值 
から使用室内の法規制值を满足するには Fig. 3 および

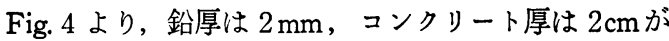
必要である。最も厳しい場合で，遮蔽体が管理区域外 を通り，遮蔽体表面が管理区域の境界となる場合を想 定してみる。この場合の法規制値は $300 \mu \mathrm{Sv} / \mathrm{w}$ が適用 され，この場合の鉛厚は $8 \mathrm{~mm}$, コンクリート厚で $7 \mathrm{~cm}$ は必要である。搬送パイプの遮蔽の実測值は施設の設 計およびこれらの設備変更に伴う法律上の許可および 変更申請5)-7) に必要である。実測値のない場合は計算 により行っているが、この場合，安全を前提にするあ まり，計算值が過大評価気味になり，過㮃遮蔽設計と なって，結果としては確かに安全ではあるが，工事費 に無駄な出費をしている場合がある。

本測定では，臨床測定で行われる持続吸入法の 555 $\mathrm{MBq} / \mathrm{min}$ と約 3 倍の $1.85 \mathrm{GBq} / \mathrm{min}$ 用いた測定であ り,この RI 量でこの程度の遮蔽が必要であるという 実測值を示した。今回測定できなかった鉄に対する遮 蔽効果, $1.85 \mathrm{GBq} / \mathrm{min}$ 以上の $\mathrm{RI}$ 量を用いた測定につ いては今後試みるつもりである。

\section{5. ま め}

PET 測定に使用するポジトロン放射 RI 搬送パイプ の遮蔽について鉛とコンクリートを用いた実測值を基 に検討した。この結果 $1.85 \mathrm{GBq} / \mathrm{min}$ 供給時，管理区 域境界規制值 $300 \mu \mathrm{Sv} / \mathrm{w}$ を満足するには RI 搬送パイ プの遮蔽は少なくとも鉛 $8 \mathrm{~mm}$ ，コンクリート $7 \mathrm{~cm}$ は 必要である。

\section{文献}

1）上村和夫 : 脳卒中, 9, 489-498 (1987)

2) 蜂谷武憲, 上村和夫, 相沢康夫, 他 : Radioisotopes, 35, 42-50 (1986)

3）山田輝雄, 若狭秀一郎, 戸田陽二郎, 他 : 日本 製鋼所技術資料-7908，pp.1-10（1983）

4）第56回放射線安全管理講習会テキスト：放射線 障害防止中央協議会, (財) 原子力技術安全セン ター編, pp.29-39 (1988)

5） 1988年版アイソトープ法令集，（社）日本アイソ トープ協会 (1988)
6）主任者のための放射線管理の実際，(社)日本ア イソトープ協会 (1983)

7）中沢幸一編 :「放射線障害防止法の解説」，日本 原子力産業会議（1974）

\section{Abstract}

Requirement for Radiation Shields of Transportation Pipe for On Line Inhalation Gases from Compact Cyclotron in Positron Emission Tomography. Takenori HACHIYA, Eiichi HAGAMI, Yasuaki SHOJI, Yasuo AIZAWA, Iwao KANNO, Kazuo Uemura, Masahiko HANDA*, Junichi MORI* and Akihisa FUKAGAWA*: Research Institute for Brain and Blood Vessels Akita, 6-10, Senshu Kubota Machi, Akita-shi 010, Japan, ${ }^{*}$ Chiyoda Safety Appliance Co., Ltd., 40-11, Hongo 3-chome, Bunkyo-ku, Tokyo 113, Japan.

In the unit housing of a compact cyclotron and positron emission CT (PET), positron emitting gas such as ${ }^{15} \mathrm{O},{ }^{11} \mathrm{C}, \mathrm{C}^{15} \mathrm{O}_{2}, \mathrm{C}^{15} \mathrm{O}$ etc. is supplied from a cyclotron to a PET room through a transportation pipe with an appropriate shield to reduce positron annihilation radiation. This paper discribes the effect of lead and concrete shields with various thickness.

Using lead or concrete shield blocks with various thicknesses, radiation leakage through the shield was measured by an ionization chamber type survey meter during continuous and constant supply of ${ }^{15} \mathrm{O}$ gas of $1.85 \mathrm{GBq} / \mathrm{min}$ concentration which is the maximum dose for clinical use. The leakage radiation measured was $213.7,56.0,15.3,5.0 \mu \mathrm{Sv} /$ week for lead shield with 1, 2, 3, and $4 \mathrm{~cm}$ thickness, respectively, and 193.3, 30.5 and $5.1 \mu \mathrm{Sv} /$ week for concrete shields with thickness of 10, 20, and $30 \mathrm{~cm}$, respectively. The present study shows that to keep less than $300 \mu \mathrm{Sv} /$ week, which is the permissible dose rate of the boundary zone around the radiation controlled area by Japan Science and Technology Agency, it is required to use more than $8 \mathrm{~mm}$ thick lead shield or $7 \mathrm{~cm}$ thick concrete for continuous supply of 1. $85 \mathrm{GBq} / \min ^{15} \mathrm{O}$ gas.

(Received May 26, 1989) 